\title{
HVMANITAS
}

\section{Viriato, herói lusitano: o épico e o trágico}

Autor(es): $\quad$ Moniz, António Manuel de Andrade

Publicado por: Faculdade de Letras da Universidade de Coimbra, Instituto de Estudos

URL

persistente: URI:http://hdl.handle.net/10316.2/27945

DOI: $\quad$ DOI:http://dx.doi.org/10.14195/2183-1718_60_16

Accessed : $\quad$ 26-Apr-2023 12:37:59

A navegação consulta e descarregamento dos títulos inseridos nas Bibliotecas Digitais UC Digitalis, UC Pombalina e UC Impactum, pressupõem a aceitação plena e sem reservas dos Termos e Condições de Uso destas Bibliotecas Digitais, disponíveis em https://digitalis.uc.pt/pt-pt/termos.

Conforme exposto nos referidos Termos e Condições de Uso, o descarregamento de títulos de acesso restrito requer uma licença válida de autorização devendo o utilizador aceder ao(s) documento(s) a partir de um endereço de IP da instituição detentora da supramencionada licença.

Ao utilizador é apenas permitido o descarregamento para uso pessoal, pelo que o emprego do(s) título(s) descarregado(s) para outro fim, designadamente comercial, carece de autorização do respetivo autor ou editor da obra.

Na medida em que todas as obras da UC Digitalis se encontram protegidas pelo Código do Direito de Autor e Direitos Conexos e demais legislação aplicável, toda a cópia, parcial ou total, deste documento, nos casos em que é legalmente admitida, deverá conter ou fazer-se acompanhar por este aviso. 
humanitas

\section{Vol. LX}

IMPRENSA DA UNIVERSIDADE DE COIMBRA

COIMBRA UNIVERSITY PRESS 


\title{
VIRIATO, HERÓI LUSITANO: O ÉPICO E O TRÁGICO*
}

\author{
António Manuel de Andrade Moniz \\ Faculdade de Ciências Sociais e Humanas \\ da Universidade Nova de Lisboa \\ mam@fcsh.unl.pt
}

\section{Resumo}

Apesar das suas incoerências históricas, o poema Viriato Trúgico, de Brás Garcia de Mascarenhas, é uma brilhante homenagem do poeta barroco português ao arquétipo lusitano da resistência heróica à invasão romana do século II a. C.

De facto, Viriato, neste poema, brilha como exemplo do integer uir, da consagração do líder à sua comunidade, através da fides, paupertas, grauitas, concordia, clementia, liberalitas, auctoritas, gloria.

Palavras-chave: herói, épico, luta, exército, resistência, glória.

\section{Abstract}

Despite the historical incoherencies, the poem Viriato Trágico, by Brás Garcia de Mascarenhas, is a brilliant homage from Portuguese baroque poet to Lusitanian archetype of the heroic resistance to Roman invasion in b. C. $2^{\text {nd }}$ Century.

In fact, Viriatus in this poem shines as a stoic exemplum of integer uir, of the consecrate leader to his community by fides, paupertas, grauitas, concordia, clementia, liberalitas, auctoritas, gloria.

Keywords: hero, epic, struggle, army, resistance, glory.

* Conferência apresentada em 11 de Agosto de 2006, no Colóquio "Ideas", no âmbito dos Festivais de Teatro de Mérida. 


\section{Introdução}

Viriato é um herói lusitano, sempre presente no imaginário português. A sua heróica resistência ao domínio romano é símbolo paradigmático de todas as lutas nacionais, designadamente as da crise de 1383-85, contra a invasão castelhana; as guerras da Restauração, contra o domínio filipino (1640-1668); a da chamada Campanha Peninsular, contra as invasões napoleónicas (1807-11).

No entanto, não são abundantes as produções literárias que evoquem o grande herói lusitano. Sobressai, antes de todas, a breve referência camoniana ao "Pastor" que, no poema épico Os Lusíadas, "Se vê que de homem forte os feitos teve, / Cuja fama ninguém virá que dome, / Pois a grande de Roma não se atreve" (Os Lus., III, 22, 2-4). Sobressai também com o nome do herói o poema de Fernando Pessoa, no seu livro Mensagem. A linguagem utilizada apela à "memória" do "instinto" heróico", numa linguagem simultaneamente fundacional e neofundacional ${ }^{2}$, inspirada na metáfora cosmogónica da Aurora, da "fria / Luz" da "madrugada", da "antemanhã", como um "confuso nada" ainda". Como Pessoa, também Miguel Torga ${ }^{4}$ evoca os heróis ibéricos, de Viriato a Séneca a Unamuno, Picasso, Pessoa e Lorca, passando por Cid, Inês de Castro, Nun'Álvares, o Infante, Torquemada, o Príncipe Perfeito, Bartolomeu Dias, Vasco da Gama, Fernão Magalhães, Afonso de Albuquerque, Cortez, Loiola, Santa Teresa, Camões, S. João da Cruz. D. Sebastião, Cervantes, António Vieira, Goya e Herculano.

A grande produção consagrada ao herói lusitano é, porém, o poema heróico Viriato Trágico, de Brás Garcia de Mascarenhas (1596-1656), publicado postumamente em 1699. Nascido em Avô, serra da Lousã, o poeta, também autor do inédito Ausências Brasílicas, depois de uma mocidade

1 "Se a alma que sente e faz conhece / Só porque lembra o que esqueceu, / Vivemos, raça, porque houvesse / Memória em nós do instinto teu" - Fernando Pessoa $\left(1979,13^{\text {a }}\right.$ ed.): 26 ( $1^{\text {a }}$ quadra $)$.

2 "Nação porque reencarnaste, / Povo porque ressuscitou / Ou tu, ou o de que eras a haste - / Assim se Portugal formou" (Ib., $2^{a}$ quadra).

3 “Teu ser é como aquela fria / Luz que precede a madrugada, / E é já o ir a dever o dia / $\mathrm{Na}$ antemanhã, confuso nada" (Ib., $3^{\mathrm{a}}$ quadra).

${ }^{4}$ Cf. Miguel Torga $\left(1965,2^{a}\right.$ ed.). 
aventureira, que lhe levou ao cárcere, donde se evadiu, embarcou para o Brasil em 1623, onde participou em negócios e no exército que combateu os Holandeses, em 1630. Tal experiência, reflectida no seu poema, permite-lhe, no regresso a Portugal, envolver-se nas guerras da Restauração como capitão e governador da praça de Alfaiates, província da Beira, não deixando, uma vez mais, de sofrer a prisão, no castelo de Sabugal, donde sai para a sua terra natal. Pôde aí encontrar as condições favoráveis para a escrita do seu poema maior.

Vamos acompanhar um pouco o percurso do herói lusitano na pena deste poeta barroco português.

Editado por Bento Madeira de Castro, cavaleiro professo da Ordem de Cristo, na Oficina de António Simões, impressor da Universidade de Coimbra, e oferecido do rei restaurador, D. João IV, este extenso poema em oitava rima, constituído por 20 cantos, foi reeditado em fac-simile por José Vitorino Pina Martins e pela Fundação Calouste Gulbenkian, em 1996. Nele o maravilhoso alegórico combina com o interesse da acção militar e dos conflitos amorosos, nele as fontes históricas romanas interligam-se de modo fluente e natural com o imaginário poético. Dirigindo-se "Ao Leitor", o editor refere-se sumariamente a essas fontes, sem, no entanto, as mencionar. Trata-se provavelmente do Livro VI da Iberica, de Apiano de Alexandria (fim do séc. I d.C.), que terá bebido grande parte da sua informação em Possidónio e em Políbio, bem como de Diodoro Sículo, Floro e Orósio, entre outros.

Apesar de o título sugerir a proeminência da vertente trágica da construção do herói, é, sem dúvida, a dimensão épica que domina este poema, sendo, sobretudo, reservado para o último canto, como é natural, o tratamento desta vertente, de acordo com o desenlace biográfico do protagonista.

Vamos, pois, acompanhar o percurso desta construção, à luz da leitura seiscentista deste poeta barroco.

5 "[...] contentandofe com as compendiofas noticias, que em louvor de feu invicto animo, \& grandes victorias referem os Chroniftas do Império Romano" (J.V. de Pina Martins 1996: “Ao Leitor”). 


\section{O herói épico}

A proposição canta não apenas o "Pastor" lusitano, mas também a dialéctica dualidade "Amores, \& Armas", de acordo com a vitalidade humana dos maiores instintos, simbolizados no mito amoroso do par Afrodite/Ares. Trata-se de um topos clássico, contemplado nas epopeias, desde Homero a Camões.

Por sua vez, a função dirigente do herói cantado é representada pela sua ocupação quotidiana, a pastorícia, como no paradigma bíblico do rei David e no serviço teológico da Hierarquia da Igreja, a chamada pastoral. $O$ "reino de Deus" é reiteradamente sublinhado pela expressão "pequeno rebanho" e pela parábola evangélica do Bom Pastor. É esse "cajado" que no poema é erguido como "ceptro de Hefpanha" (Viriato Trágico, I, 13:8).No canto VIII, a propósito da Fortuna, o próprio poeta fornece numerosos exemplos de reis, ou equivalentes, que foram pastores e filhos de gente humilde ${ }^{6}$. O mesmo canto desenha o retrato físico e psicológico do herói, "como o defcrevem os melhores, / E mais acreditados Efcritores" (VIII, 18-7-8). Salienta-se a estatura gigantesca do seu corpo, o nariz aquilino, o engenho agudo, a austeridade de carácter, a liberalidade, a moderação, a bondade do trato $^{7}$. $O$ elogio das suas qualidades militares faz

${ }^{6}$ Agátocles, imperador Górdio; Tamorlan; Bonoso; Arcasses; Primislau; Giges; Sérvio; Arquelau; Hipérbalo; Teléfanes; Dario; o cônsul Basso; o imperador Valentiniano; Ptolomeu do Egipto; Artaxerxes; Basílio de Bizâncio.

7 "Foy de efpadoas, \& pernas muy furnidas / Em proporção ao corpo gigantado / Com fobrancelhas groffas, \& cahidas / Que o fafião fevero, \& refpeytado; / Barba crefpa, gadelhas retorcidas / Aquilino o nariz, mas bem formado, / Grandes olhos \& rofto, Erguidas veas / Nas mãos nervofas, de cabellos cheas. // Duro de membros, como a patria ferra, / De grandes forças, \& de engenho agudo: / Serviolhe fempre de colchão a terra, / E de branda almofada o duro efcudo; / Porque armado dormia em Paz, e em Guerra, / Tão pouco, que por fi velava tudo; / Nunca já mais a Aurora o precedia, / Porque fempre no campo armado o via. // Prodigo de ouro, de honras ambiciofo, / Eftas appetecia, aquelle dava, / Que ajuntando infinito bellicofo, / Liberal aos foldados o efpalhava; / Sempre em defpojos pobre, \& caudalofo / Como Rio crecia, \& mingoava / Fazendo em vez da prata, em vez de ouro, / De coraçoës comprados feu thefouro. // Pouco oftentofo ao comum veftia / Que nunca em traje foy differençado / de qualquer dos foldados, que trafia / De quem foy fempre eftranhamente amado; / Amava-os 
dele a glória de toda a Espanha ${ }^{8}$, de modo a merecer os epítetos por antonomásia de "Aquiles lusitano" (IX, 99:3) e "lusitano Marte" (X, 12:1). Como político, não só governou, mas também contribuiu para a civilização da sua comunidade através da sua actividade legislativa ${ }^{9}$ O elogio do poeta ao seu governo, após a consideração dos vários modelos políticos $(X, 2-12)$ e a crítica às várias formas de má governação $(X, 1)$, concilia a sua autoridade de líder com a sua afectividade de pai, irmão, amigo e companheiro $^{10}$, o seu desprendimento material e espiritual com a sua liberal generosidade ${ }^{11}$.

como filhos, \& os regia / Como bom Pay, tão brando, \& moderado, / Que nenhum fe atrevia adeffervilo / Tratando fo de amalo, \& de feguillo" (VIII, 19-22).

8 "Foy o mais animofo, \& mais aftuto / Capitão, que fe fabe entre os Antigos / Que não ouve nenhum tão refoluto / Em cometer, \& evitar perigos, / concedido lhe foy tal attributo / Por bocas de feus próprios Inimigos, / Que verdades não há mais apuradas, Que as que vem dos contrários confeffadas. // Lufitania lhe deve \& toda Hefpanha / A gloria militar, que lhe eclypfava / Antes delle, qualquer Nação eftranha, / Que com a ajuda fua à conquiftava. / Não me darão contra Hespanhoës façanha / De quantas nelle a a Fama celebrava, Que antigos Eftrangeyros alcançaffem, / Sem que os Seus naturais os ajudaffem." (VIII, 23.32-33).

9 "Foy Viriato o primeyro filho della, / Que a deu a conhecer por mais Guerreyra; / Legislou, imperou, \& venceo nella / Toda a potencia bellica eftrangeyra: / Era antes delle Hefpanha hua donfella / Requeftada de Gente forasfteyra / m cuja pretençaõ prevalecia / Aquelle, a que elle mais favorecia" (VIII, 33).

10 "Se bem do noffo Lufitano Marte / O governo Monarchico julgaffem / Nem Defpotico foy, mem teve parte, / Porque de Ariftocratico o notaffem: / E fe a governos, que ambição, \& arte / Oftentão hoje, o feu bem comparaffem / Achàraõ que na Paz, \& na Conquifta / Deyxava todos a perder de vifta.// [...] Com tanta authoridade, \& tanto brio / imperou grave, caftigou humano, / Que Paftor de Vaffallos o chamara / Quem, que o fora de ovelhas, ignorara. // Como Pay, porque o foy muy verdadeyro / Da Pátria, os Filhos della cariciava; / Como Irmaó, como Amigo, \& Companheyro, / Os foldados regia, \& fe tratava. / Orelhas nunca as dava ao lifongeyro, / Nem a queyxofos pobres os negava; / Que com rezão fua Rezão de Eftado / Fundou fempre em amar, \& fer amado" (X, 12.13: 5-8; 14).

11 "Privado nunca o teve, que a privança / Monarchas cega, \& faz aborrecelos, / E dos Vaffallos tira a confiança / Do galardão, que anima a defendelos. / Sua guarda era fua efpada, \& lança. / Seus regalos fugir de appetecelos; / Aos feus não poz tributos; tributários / Por muytas vezes fez muytos contrários. // A fua cufta pagava fempre a gente, / Que por tantas virtudes o feguia. / Efte era o feu governo dignamente / Merecedor de grande Monarchia" (X, 15. 16:1-4). 
A série de epítetos "Rayo do monte, \& da campanha, / Terror de Italia, \& do mundo efpanto, / Gloria de Portugal, honra de Hefpanha; / Triumphante da Águia, que triumphando tanto / Tanto a feus rayos timida fe acanha"12 espelha hiperbolicamente o propósito glorificador do poeta épico.

A écphrasis do templo da Fama (Cf. VIII, 71-74) consagra esteticamente a glorificação do herói cantado ${ }^{13}$.

A resistência lusitana à "belligera Roma" (I, 10:1) é contabilizada em "dezoito lufytros" (I, 13:1) até à intervenção de Viriato ${ }^{14}$, o que constitui um exagero cronológico, em cerca de 40 anos, pois aquela resistência é iniciada em 193, no fim da II guerra púnica e a intervenção do caudilho da Beira ocorre em 147. Outro marco cronológico é a indicação de "defanove feculos inteyros" 15 relativa à distância histórica entre os acontecimentos narrados e a época do narrador.

A ocupação da caça, atribuída por Diodoro (Cf. Diodoro, XXIII, 1) a Viriato, é aproveitada pela "fugitiva Nympha" para, no Templo da deusa Ocasião, simbolizar a "mortal guerra" em que agora se encontra empenhado ${ }^{16}$. Com ela, o ingénuo serrano aprenderá as tácticas militares que lhe darão "Immortal fama com Nações eftranhas"17.

${ }^{12}$ I, 1:2-6.

13 "No frontefpicio, \& lados, que adornavão / eftatuas mil de perfeyçoës difcretas, Bem como em Efcatombe, fe contavão / Cem portas, cem janellas, cem trombetas; / Boas, \& mas fortunas publicavão, / Que qual de órgão real, teclas fecretas / A todas do interior a loquâz Fama / Por boas cento efperitos derrama." (VIII, 72).

14 "Dezoito luftros de annos pelejando / Toda a potencia bellica Romana, / Não pode, jà perdendo, \& já ganhando, / Acabar de render o Lufitano: / Quando do centro (que ditozo!) quando / Da Beyra (ò Beyra em tudo soberana!) / Viriato empunhou (ventura eftranha!) / O cajado, que foy ceptro de Hefpanha." (I, 13).

15 "Há defanove feculos inteyros, / Que as armas de Viriato floreceraõ; / E ainda agora em bons livros, \& letreyros, / Se reprova, o que mal delle efcreveraõ. / Tempo virá, que fruftre lifongeyros, / E lifongeados, que favor lhe dèraõ, / Cada qual com valor faça o que deve, / Porque de quem mal obra, mal fe escreve" (II, 3).

16 "Reftituida em fim fua harmonia, / Refrigerados jà os membros bellos / Da fugitiva Nympha, affim defia: / Tens, Paftor, a Occafião pellos Cabellos; / Jà que fabes feguir com tal porfia, / Sabe-te aproveytar de teus desvellos, / Que a caça, que tos caufa nefta ferra, /Vivo retrato he da mortal guerra" (I, 44).

17 "Nefta, que agora abraza effas campanhas, / Que daquî eftàs vendo, te aparelho / Immortal fama com Naçções eftranhas, / Se quizeres feguir o meu 
No final do Canto II, Lísias oferece-se para contar, em analepse, a história da guerra entre Roma e Cartago, que teve a sua origem em Espanha. Assim, o Canto III, intitulado "Antiguidade", depois de referir a dupla vitória lusitana sobre os Fenícios de Cádiz e a entronização de Viriato como Rei dos Celtas $^{18}$, apresenta uma aliança entre Aníbal e o herói ibérico ${ }^{19}$, chegando a fantasiar a participação deste nas guerras púnicas $^{20}$ e a atribuir aos Lusitanos a vitória de Canas ${ }^{21}$.

O canto IV, intitulado "Surpresa", devido à vitória lusitana sobre Bobadela, enumera alguns heróis clássicos ao lado de Viriato ${ }^{22}$, ligados entre si pelos vínculos sagrados do amor pátrio ${ }^{23}$. Na ambiência política da época da escrita, o poeta, depois de narrar várias façanhas, faz aclamar o chefe lusitano como "Reftaurador, \& Pay da pátria"24. A festa da vitória não impede, porém, a prevenção e a fortificação ${ }^{25}$. Mas o que mais impres-

confelho, / Mas porque te criafte entre as montanhas, / Ignorante do mundo, que he jà velho, / Vem comigo, \& verás delle em meu Templo / Tudo o que bafte pêra teu exemplo" (I, 45).

18 "Os Celtas, que de todos defconfião / Por feu Rey a Viriato levantaraõ" (III, 53:1-2).

${ }^{19}$ Aníbal "A Viriato vay ver, que o Sceptro tinha / Dos Celtas, \& com elle pazes trata" (III, 58: 1-2).

20 "El-Rey Viriato Cavalleiro raro / $\bigcirc$ [a Aníbal] fegue com muyta grã Cavallaria, / [...] Não ficou Lufitano em armas claro, / Que Aníbal não levaffe em companhia, / E com eftes, como elle confeffava, / As mayores victorias alcançava" (III, 62).

${ }_{21}$ "Foy a quarta batalha junto a Cannas, / Pobre Aldeã, por elle muy notória, / Da qual às noffas Armas Lufitanas / Se deve a mayor parte da victoria. Ali morreo Viriato entre as Romanas / Lanças, pêra viver fua memoria: / fincoenta mil Romanos acabaraõ / Nella, \& cativos doze mil ficarão" (III, 64).

22 "Exemplo feja o noffo Viriato, / Theféo, Agefilào, Dion, Servilio / [...] Scipioẽs, Decios, Filenas \& outros muitos" (IV, 63: 1-2.8).

23 "Que todos derão pella Pátria a vida, / Ou a morrer por ella fe arrifcarão" (IV, 64: 1-2).

24 "De pois de tudo a ferro eftar rendido / Viriato, que façanhas tinha obradas / Se moftra qual vifmho agradecido / As Gentes Lufitanas despojadas, / Tudo o que feu fe achou, reftituido / Lhe foy; do que ficarão tão pagadas, Que cada qual por feu fenhor o acclama / Reftaurador, \& Pay da patria o chama" (IV, 87).

25 "Não ceffa a prevenção, nem ceffa a fefta, / Que muito fefteja, \& fortifica" (IV, 1-2). 
siona é a piedade fraternal que impele à criativa doação de um hospital destinado aos pobres ${ }^{26}$.

São célebres as tácticas militares usadas por Viriato, destinadas a provocarem a instabilidade e a desorientação das forças ocupantes. São tácticas de guerrilha, do chamado "bate e foge", que os movimentos emancipalistas de todo o mundo têm vindo a repetir. Como assinala o Canto II, o chefe lusitano "Occulta a Gente de huma, \& outra banda, / Porque a Romana tarde a reconheça, / A qual da certa morte defcudada / Vem a cahir em meyo da cilada" (II, 64: 5-8). A astúcia é, pois, a arma inteligente dos invadidos perante a manifestação da força disciplinada do inimigo. Desta astúcia faz parte o recurso à simulação do traje do adversário: "E das prefas folicito procura / Armar todos os Lufos à Romana / Que mil vezes o traje a vifta engana" (II, 104: 6-8). O génio inventivo e táctico suprime, assim, a falta de recursos bélicos e a inferioridade da preparação militar ${ }^{27}$ : "Viriato inventando novas traças / De Guerra, affalta a muytos defcuydados / supprindo com aftucia peregrina / A falta da Mavorcia difciplina" (II, 122: 5-8). É, ainda, a astúcia que norteia Viriato na expectativa de vencer Pláucio, "Que fempre aftucia foy mãy da ventura (IX 42:4).

Associada à astúcia, está a prevenção, ambas fruto da prudência, pelo que o poeta o designa como o "Capitão mais prevenido" em toda a Espanha $^{28}$.

Por outro lado, o instinto de agressividade dos Lusitanos, aliado à motivação da sua luta, constitui uma natural condição de sucesso militara ${ }^{29}$,

26 "E huma principal Júlia modefta / As portas à fua cufta reedifica. / Permanece hum letreyro antigo defta / Que muyto claramente o teftifica; / Outro de hum Hofpital a pobres dota: / Tão antiga hé a piedade, tão devota!“ (IV, 89: $3-8)$.

27 "Não valeo aos Romanos a experiência / Militar, em que muy verfados eraõ; / Que os noffos com valor, \& pouca fciencia / Depois de vencedores, os vencerão / Vinte mil que fizerão refistencia / A mãos de Lufitanos perecerão: / Foge Mumio, feos Deofes blasfemando, / Riquezas mil ao Vencedor deyxando" (III, 107).

28 "Não ouve Capitão mais prevenido / Do que foy Viriato, em toda Hefpanha; / Nem ella o conheceo mais entendido / Em a faber com diligencia eftranha" (XVI, 65: 1-4).

29 "No campo, que de fangue fe alagàra, / Viriato o Tropheo guerreyro arvòra, / E fò defcança em quanto fe prepara, / Pêra marchar a Gente vencedora. / 
ainda que o poeta não deixe de assinalar, em jeito de crítica, o excesso de tal agressividade que impede a paz até entre concidadãos:

"por mais que outrem nos vença, ou que vençamos,

Efta grã tacha os Lufitanos temos;

Prefto do bem da Paz infaftiamos,

E prefto o mal da Guerra appetecemos.

Como hãode faltar Guerras fe as bufcamos?

Como hà de aver paz fe a não queremos?

Sempre fomos de pazes incapazes,

Por que nunca cõ nofco temos pazes" (III, 82).

Por isso, é assinalável o papel unificador de Viriato, sobretudo perante a fuga vergonhosa do inimigo ${ }^{30}$, que ocorre no canto $\mathrm{V}$, intitulado "Emulação", devido ao aplauso que o caudilho lusitano recebe em toda a Espanha ${ }^{31}$.

Astucioso, ainda, é o comportamento do herói épico, qual o de Ulisses, entre os Gregos, ao aconselhar uma táctica de simulação de paz ante as propostas de Galba, argumentando que, por um lado, negar a paz seria temeridade, mas, por outro lado, desistir da guerra seria covardia ${ }^{32}$.

Em três partes o Exercito fepàra, / E abalaõ todos traz a quarta Aurora, / Que fobre grã victoria oufada Gente / Difficeis Praças rende facilmente" (XVI, 81).

30 "Põem-fe os noffos em fuga vergonhofa, / Depois que feramente pelejarão; / Sós celtas, \& Vetoës Gente animofa, / Com ordem militar fe retirarão. / Viriato, que vé tão pavorofa / Defordem, recolhendo os que ficarão, / Aos feus, que fempre feparou guerreyro, / Vnindo-os, fe retira o derradeyro" (V, 70).

${ }^{31}$ A Galba, destroçado, "Segue-o muy pouca Gente fugitiva, / Deyxando na mortífera campanha / A mayor parte morta, \& a mais cativa, / E Viriato aplaudido em toda a Hefpanha, / Sem que lhe negue emulação nociva / A palma, \& gloria de tão gram façanha, / Com que allivia feus paffados nojos / Lufitania, que fe enche de defpojos" $(\mathrm{V}, 86)$.

32 "Viriato interpondo a authoridade, / Socegando o tumulto, affim difia: / Negarmos Paz ferà temeridade, / E defiftir da Guerra, covardia. / Na Paz vejo muy grã difficuldade, / Porque muy vergonhofa Paz feria / A que nos Galba agora concedeffe / Não vendo em campo Gente, a quem temeffe. // He meu parecer que entretenhamos / Galba, fingi[n]do que fó Paz queremos, / Em quanto aftutos forças ajuntamos, / Com que as muytas, que traz, contrapefemos, / Sem as quais a 
O pretor romano, porém, depois de prometer aos Turdetanos boas terras de cultivo, separa-os para lhes impor o desarmamento ${ }^{33}$, não deixando cinicamente de lhes declarar a sua preferência pela paz ${ }^{34}$. O resultado é a ingénua queda no laço ardiloso armado pelo inimigo ${ }^{35}$, merecendo da parte do narrador a interpelação recriminante aos "simples cordeyros" e às "ovelhas inocentes" que se deixaram ludibriar pelos "lobos carniceyros"36, cuja barbárie é denunciada como excessiva ${ }^{37}$. Mais uma vez, a função consolatória de Viriato anima os companheiros "A fepultar a Gente degollada (VI, 91: 2). Segue-se o juramento de vingança (Cf.VI, 104-105), sentimento que dá título ao canto VII.

Apesar da interligação do herói épico à função guerreira, o poeta barroco português, depois de apresentar considerações morais sobre a vingança (Cf.VII, 1-5), faz representar, na écphrasis do templo de Marte, a Paz, "em Minerva figurada", ajoelhada a seus pés, "Como que paz pedia pêra a Gente", não deixando de a contrastar com a soberba do leão, a inveja da serpente, o fumo da vanglória e o ardor da ambição, abraçando o

partido não venhamos; / Que nunca em jogo tal bom o teremos, / Porque aquelle que o faz, boas contas deyta / Pois não fe arrifca, como quem o aceyta" (VI, 48-49).

33 "Galba, depois de tudo concluído, / Aparta os Turdetanos defarmados / Com outros, a quem tinha prometido / Bons campos, huns dos outros feparados: / E logo com treydor rizo fingido / Lhes diz: jà eftareis defenganados / De que vos trato a todos como Amigos, / E de que ceffaõ jà voffos caftigos" (VI, 67).

34 "Quanto melhores faö pazes, que Guerras! / Porque eftas defocupaõ os poffeffores, / E aquellas vos daràõ campos por ferras, / Que prefto delles vos fereis fenhores. / Deyxay as rmas, \& deyxay as Terras, / Que terras vos darey muyto melhores: / Ide quantos quizerdes habitalas, / Que a todos quantos fordes, quero dalas" (VI, 68).

35 "Fica Galba no campo muy de efpaço / Vendo a caça, que vay dexeyta ao laço" (VI, 72: 7-8).

36 "Adonde caminhais fimples cordeyros, / Adonde ides ovelhas inocentes? / Como vão os rebanhos dos carneyros / Ao talho caminhando muy contentes! / Fugî, fugî dos Lobos carniceyros, / Que vos ides meter entre feus dentes. / Tristes das Mays! Que hão de faber, coytados, / Que em tres açougues foftes degolados" (VI, 73).

37 "Quantas treyçoens, \& quantas falfidades / Padecerão effoas innocentes, / A todas excedeo a barbaria / Treydora dos Romanos nefe dia" (VI, 76: 5-8). 
Globo, registando, com lucidez revolucionária, a futilidade das conveniências políticas, ocultadas sob o eufemismo das Razões de Estado ${ }^{38}$. Tal como na figura de Eneias, no poema virgiliano, o herói épico passa a ser associado aos projectos de paz $^{39}$. Como o Velho do Restelo, n' Os Lusíadas, o poeta barroco português invectiva o espectro da guerra, com as suas consequências sociais, como a fome, a peste, os estragos fisicos e psicológicos, considerando-a, em suma, "O theatro univerfal de defventuras"40. $\mathrm{E}$, perante a sua falsidade, põe em causa a transitoriedade das glórias mundanas, das vitórias e triunfos militares ${ }^{41}$, a invenção dos instrumentos bélicos ${ }^{42}$ e a insensatez das festas em sua honra ${ }^{43}$. No entanto, Viriato, invectivando a

38 “A Paz, que era em Minerva figurada, / Cuja Imagem devota, \& reverente / Se moftrava a feus pès ajoelhada, / Como que paz pedia pêra a gente; / A foberba no Leão symbolizada, / A inveja em figura de ferpente / Defvanecendo hua, outra arraftando, / A feus lados a eftavaõ defprefando. // Na groffa lança fobre hum limo ondeado / Se via a Vangloria em fumo desfazendo; / No forte efcudo a Rezaõ de Eftado / Em figura de efponja eftava ardendo; / Ardia a ambiçaõ, tinha abraçado / Hum globo, em que fe eftava o mundo vendo, / Com efta letra na circunferência: / Toda Rezão de Eftado hé conveniencia” (VII, 41-42).

39 "Tu, Romano, sê atento a governar os povos com o teu poder $/$ - estas serão as tuas artes - a impor hábitos de paz, / a poupar os vencidos e derrubar os orgulhosos" (Aen., VI, 851-853).

40 "O guerra, guerra, quem nunca te vira, / Nem foubera a que partes evaporas / O efpanto, a fome, a pefte, o eftrago, a ira / Da vida algozes, do defcanfo efporas, / Mãy da cobiça, fonte da mentira, / dos dias confufaõ, horror das horas, / Centro da inveja, lago de amarguras, / O theatro univerfal de defventuras!" (XIV, 106).

41 "De que fervem mortíferas victorias, / Triumphos, \& tropheos, que em fim recitas, / Cifrando nelles as mundanas glorias, / Se todos faõ infernos de defditas? / Ah falfas alegrias tranfitorias! / Ah caduca ambição, q. as folicitas! / Comprando a fangue applaufos de cohortes, / Que dão mais vivas a quem dá mais mortes!" (XIV, 107).

42 "Que de inftrumentos bellicos inventão / Os homens nefcios contra a propria vida! / E talvez em feus corpos exprimentão / Armas lavradas contra os homicidas. / Eftas, q. os victoriofos de hoje alentão / Dos vencidos artífices regidas / Se virão hoje, \& á manhã peyores / Servirão de matar aos matadores" (XIV, 108).

43 "Eftranho \& louco feftejar! Eftranhas afflicçoës, donde entre mortais trefpaffos / A três filhos, pedaços das entranhas / Vi fazer entre as armas em 
fraqueza lusa ${ }^{44}$, proscreve realisticamente uma paz insidiosa e covarde, em detrimento de uma paz generosa e liberal (Cf. VII, 59-64): "Todo o que pede paz vencido fica, / Que hè toda a paz dañofa a quem a pede, / Honrada, \& proveytofa ao que a concede" (VII, 60: 6-8).

Assim, perante as vitórias de Viriato, é todo o Capitólio que treme $\mathrm{e}^{45}$ e, no canto VIII, intitulado "Fortuna", é o severo Catão-o-Velho (Cf.VIII, 92-96) que, no Senado romano, sente necessidade de apelar ao castigo do "fegundo Anibal", como the chamara Cláudia, esposa de Vitélio (Cf. VIII, 86:6), para não se dilatar a guerra na longínqua Espanha, pois "para grandes males, grandes remédios" e "não vence quem não faz juftiça" 4 .

Mas é o espírito indomável e persistente do lusitano que melhor explica a sua capacidade de vencer, como depois de Quinto Pompeu conseguir romper o seu exército: "Sabey, que nunca me vereis vencido" 4 . Retirar para voltar a atacar é a palavra de ordem em todos os reveses ${ }^{48}$.

pedaços! Os que não padeceis magoas tamanhas Se hé que dellas zombais, detende os paffos; / Volvey os olhos, \& vereis a pares / Arder Cidades, Villas, \& Lugares" (XIV, 110).

44 "E jà começa a Gente fediciofa / A propor pazes, \& dizer que as querem / Com quaifquer condiçoës, que as concederem" (VII, 58: 6-8).

45 "O Capitolio treme, tremem quantas / Torres o cingem, tremendo affombradas / Tantas pompas triumphais, Eftatuas tantas, / A Heroes invenciveis confagradas / Viriato fe atraveffa nas gargantas / Dos varoës principais, \& das turbadas / Familias Senatorias, que parentes / Tinham na Hefpanha em cargos preeminentes" (VIII, 77).

46 "Não convem que efta Guerra fe dilate, / Pois tão mal nos principios nos fuccede; / Manday força que a fua desbarate, / Que forte mal forte remedio pede / Casftigay o treydor, que vos abate / A honra, \& que os triumphos vos impede, / Violando as Leis, por medo, \& por cobiça, / Por que não vence quem vos não faz juftiça" (VIII, 96).

47 "Tanto que outra vez teve o campo unido, / Affim lhes falla: Valerofa Gente, / Soube Pompèo romper como atrevido, / Mas não foube vencer, como prudente. / Sabey, que nunca me vereis vencido, / Quando o não fico na occafião prefente: / Não temais, que efte Exercito fe acabe, / Que quem o deyxa vnir vencer não fabe" (XVII, 52).

48 "Lenta vos retiray, Gente Guerreyra, / Pêra o monte dos noffos occupado, / Porque quando o Pretor cortar nos queyra, / Muyto prefto o vereis dsbaratado" (XVII, 53:1-4). 
O sentido de união militar coroa este espírito indomável, provocando a retirada do inimigo ${ }^{49}$.

O espírito de clemência, virtude generosa das almas nobres, que Viriato manifesta para com Servílio e sua mulher Súlvia ${ }^{50}$, no canto II, é agora, no canto XIX, contraditado pela prática vindicativa, saída da amarga experiência da guerra, já que "Manda prefto inforcar, \& por a fio / De efpada mil Romanos, por quinhentos / Que Fabio degolou a fangue frio" (XIX, 39: 2-4).

Aliada à clementia, a liberalitas, propugnada por Séneca, no seu De Benefficiis, cuja lição o Infante D. Pedro de Portugal aproveita no seu Livro Da Virtuosa Benfeitoria, também pauta o comportamento político do chefe luso, que reparte com os seus os despojos de cuja vitória é o principal responsável ${ }^{51}$.

Finalmente, a sua frugalidade (paupertas), associada ao tópico da aurea mediocritas, confere a este herói a autenticidade estóica que lhe permite ser conhecido como o mais dedicado chefe, sem outro interesse do que promover o bem comum: "De nada fe perturba, nem fe inflama / Aquele coração nunca turbado: / Entra na Tenda, faz da terra cama, / Que efta era o feu colchão mais regalado; / E do efcudo almofada, que mais ama" (XX, 39: 1-5).

49 "O Pretor, que no alcance da bifonha / Gente por entre a firme atraveffara, / Quando a vè tão unida fe envergonha, / Manda a fua parar, \& cauto para. / Primeyro que outra vez a recomponha, / E unir poffa a que a traz deyxàra, /Vè, que marcha Viriato em meia altura / Do monte, que Minuro the affegura" (XVII, 54).

50 "Em quanto laffa affim febil fufpira / Movendo as duras penhas a piedade, / Chegou Viriato que feu pranto ouvira, / E efperança lhe deu de liberdade. / Sobre hum andor que do Idolo fervira, / Efte de Amor com muyta honeftidade / Manda em hombros fubir ao monte altivo, / Que todo o generofo he compaffivo" (II, 85).

51 "A que toca a Viriato á fua parte / Toda fe libra em armas, 6 Cavallos / Mas fe os despojos liberal reparte / He fua toda a gloria de ganhalos. Aclamado por him novo Marte / Dos feus, a nova emprefa quer levalos, / por que em quanto não chega a exercitarfe / Das aftucias procura a proveitarfe" (II, 87). 


\section{O herói trágico}

Se o herói épico é luminoso e exemplar, e por isso, representativo da areté e da uirtus aristocráticas, o herói trágico é paradigmático da condição humana, sujeita à fragilidade e ao erro (hamartia). Daqui e da insolência (hybris) ante o Destino (Moira/Fatum) provém a punição divina (Némesis): o sofrimento probatório (páthos/cátharsis) e a catástrofe.

O título Viriato Trágico é justificado pelo editor a partir do "lamentável fim que teve" o ínclito lusitano. A Proposição canta a vitória até à morte do "Triumphante da Aguia", salientando o tímido acanhamento desta que não encontra outro recurso, como único meio de eclipsar o seu triunfo, senão a traição covarde: "Tanto a feus rayos tímida fe acanha, / Que à traição, sò dormindo, o vio rendido, / Porq. defperto nunca foy vencido" (I, 1: 7-8).

A partir do canto XVII, vão-se congestionando os indícios trágicos. A carta de Messalina a Aulaces (Audax) ${ }^{52}$, um dos assassinos do herói, é considerada como o ponto de partida da ruína de ambos e da desventura de Viriato, isto é, "A tragedia mais chea de amargura"53.

A propósito do cerco de Fábio Máximo à praça lusitana de Eristana (Cf. XIX, 45-48), a morte do herói trágico é de novo anunciada como breve, a partir de uma reflexão sobre a "vil fragilidade humana", bem patente na volúvel sorte da guerra, "Que aproveytando a huns, a outros daña" 54 .

A hamartia de Viriato, na efabulação poética, resulta da sua excessiva generosidade para com Fábio Cipião ${ }^{55}$ : o pacto de paz que lhe concede no

${ }^{52}$ Cf. XVII, 95-103.

53 "Nefta carta, que foy de ambos ruina, / Confistio de Viriato a defventura, / Que tanto, antes da cava, Meffalina Cava de toda Hefpanha a fepultura. / O como lhe refponde, \& fe origina / A tragedia mais chea de amargura, / Cantaremos nos três feguintes cantos, / Se a tão poucos refumo estragos tantos" (XVII, 104).

54 "Em dilaçam tam breve, \& tam urgente / efteve, ô vil fragilidade humana! / Todo o remédio da Romana Gente, / E toda a perdiçam da Lufitana. / Tal pè da Guerra o mínimo accidente, / Que aproveytando a huns, a outros daña. / Quem cuydàra, que tam breve demora / Da morte deViriato origem fora" (XIX, 71).

55 "Cerca-os nelle Viriato eftreytamente / E como o mantimento lhes faltaffe / A inftancia de Scipiaõ Fábio confente, / Que da paz defejada fe trataffe, / Appetecida de hu, \& outra Gente / Como a de toda Hefpanha a defejaffe, / Fierão tais inftancias a viiriato, / Que orelhas deu, pella agradar, ao trato" (XIX, 73). 
cerco, por escassez de mantimentos, vai originar uma lamentação posterior $^{56}$, a da derrogação romana de tal pacto ${ }^{57}$.

O canto XX, intitulado "Tragédia", situa o desenlace trágico na tenda de Viriato, "Nos altos Pyrenéos", onde o herói "â treyção hè degollado" (XX, Argvmento). Tal feito, classificado como "horrivel", projecta a vítima na história como "memorando", "formidável, \& invencivel"58, "Igual na morte, \& feytos valerofos" "aos mais efclarecidos" 59 .

Substituindo, com intrigas, a seu irmão na direcção do exército romano, Cipião admite à sua mesa Dictaleão, Minuro e Aulaces ${ }^{60}$, prometendo-lhes grandes mercês, pela cabeça de Viriato ${ }^{61}$.

Fiado na lealdade dos seus mais importantes colaboradores, subitamente transformados em "embayxadores / Da morte", "Contando embuftes proprios de treydores / Sobre as pazes, que dizem negocearão / Tirando condiçoës de vencedores" ${ }^{2}$, o ingénuo herói trágico comete o

56 "Veyo-fe a concluir, que fe ficaffe / Cada hum com o que tinha conquiftado, / Com tanto, que Viriato fe moftraffe / Sempre de Roma Amigo, \& do Senado; / Que cada qual em paz fe retiraffe, / Sem procurar vingança do paffado; / E jurada efta paz foy feftejada, / Pera fer brevemente lamentada" (XIX, 74).

57 "Scipião irmaõ de Fabio, que o rogara / Mais que todos, que as pazes aceytaffe, Sendo aquelle, que mais as defejara, / Porque de certa morte fe livraffe; / Como o primeyro foy, que as procurara, $/ \mathrm{O}$ primeyro quis fer que as derogaffe; $/$ De accuzar o irmaõ proprio fe não corre, / E he moeda de então, que agora corre" (XIX, 80).

58 "Caufa mayor a deu a feyto horrível, / Que subindo de humilde a memorando, / Morreo por formidavel \& invencível, / Prefto veremos onde, como, \& quando" (XX, 6: 1-4).

59 "Igual na morte, \& feytos valerofos / Foy Viriato dos mais efclarecidos; / $\mathrm{Na}$ origem della não, fe não me engano; / Porque não foy vencido, nem tyrano" (XX, 5: 5-8).

60 "Deyxa contra Scipião, tres Eftrangeyros / Por eftes quatro [Vandermilo \& Balaro confelheyros (...) / Com Apuléo, \& Briféo] na fecreta mefa / Admittio, Dictaleão, Minuro, Aulaces, / Inimigos occultos, \& fugaces" (XX, 14: 5-8).

61 "Refume-fe por fim, em que, fe deffem / Prefto a morte a Viriato, thes daria. / Os trez melhores cargos, que efcolheffem / Entre os muytos, \& grandes que provia: / Dez mil marcos de prata, que pudeffem / Repartir entre fi, \& thes faria / Grandes mercès que o grande irrefoluto / Nunca promete pouco, nem dà muyto" (XX, 26).

62 "Chegão-lhe aqui os trez embayxadores / $\mathrm{Da}$ morte, porque fó della trataraõ, / Contando embuftes próprios de treydores / Sobre as pazes, que dizem 
erro (hamartia) de não admitir na sua tenda qualquer guarda que pudesse protegê-lo de eventuais ataques ${ }^{63}$. Mais uma vez, o amor é responsabilizado pelo assassínio (miasma), que é lamentado como "morte trfte", em contraste com a dita da vítima, que a não sentiu ${ }^{64}$ :

"Aulaces por amor de Meffalina, Que em prefentes idèas o animava, Tira de hua catana larga, \& fina, Que pera tal effeyto aguda eftava: E como efpiga fega repentina A cabeça, que Hefpanha fuftentava, E que afpirava a fer muyto depreffa XX, 45 .

De toda Europa fingular cabeça" (XX, 45).

Mas o Destino (Moira/Fatum) acaba por castigar (Némesis) os responsáveis por tal acto hediondo, como que numa reposição da ordem violada (Díke). Messalina começa por recusar casar-se com um traidor (Cf. XX, 54).

Abandonado pela amante ${ }^{65}$, Aulaces, envolvido na trama das contradições do amor, torna-se o agente da sua autopunição, suicidando-se estoicamente $^{66}$ e oferecendo poeticamente a vida a quem the causou a morte ${ }^{67}$.

negocearão / Tirando condiçoës de Vencedores; / E que elles, \& Scipião logo as jurarão, / Obrigando-fe os trez a que as juraffe / No mefmo dia em que o Fecial chegaffe" (XX, 30).

63 "Fundava-fe Viriato em fer amado / E nunca tanto o foy algum Guerreyro: / Mas por não fer dos naturais guardado / Veyo a morrer a maõs de hum Eftrangeyro: / Sendo feroz Leão foy degollado, / Como fe fora tímido cordeyro, / Sobre feu próprio efcudo" (XX, 48:1-7).

${ }^{64}$ " [...] ò morte trifte! / Mas ò ditofo tu, que a não fentifte!" (XX, 48: 7-8).

65 "Pofto em fua prefença o trifte Amante, / Suas finezas pallido repete: / Ella por fóra rigido diamanate, / Dentro, qual cera, ao fogo fe derrete: / eftà rendida, finge-fe arrogante, / Com a lingoa nega, com acçoës promete, / Com a voz defpede, com os olhos chama, / Vay, fica, quer, não quer, ama, \& desama" (XX, 55).

66 "Aulaces com payxão perdendo aas cores, / Arrancando o punhal, diffe iracundo: / Quem foy treydor ao rayo dos treydores, / Acabe affim, que affim caftiga o mundo. / E por trez vefes defprefando as dores, / $O$ peyto fe paffou tão furibundo, / Que quando os trez Centurioës acodirão, / Defmayou, \& cahir a hum tempo virão" (XX, 57).

67 "Gentil fenhora [lhe diz flebilmente] / E vida amada, em morte agradecida, / Contente morro de vos ter prefente, / E prefente vos faço defta vida [...] // 
Depois de lamentar a sua sorte, e invectivando Cipião ${ }^{68}$, aquela que se encontrou "Viuva, nem cafa, nem Donfella" (XX, 64: 2), tirando o punhal (Cf. XX, 66) põe também termo à sua vida, consumando mais uma tragédia amorosa (Cf. XX, 71). Ergue-se a sepultura para os dois amantes (Cf. XX, 74), enquanto se procede à prisão dos "tres facinorofos Eftrangeyros" ( XX, 80).

Com a falta do seu caudilho, desanima o exército lusitano: "Faltando-lhe a cabeça, em hum inftante, / Todo o brio perdeo, toda a fciencia" (XX, 83: 3-4). Tal carência é devidamente assinalada, em jeito de balanço final: "Deyxou a toda a Hefpanha faudofa / Roma vencida \& mal acreditada, / Cheas de altas façanhas as Hiftorias, / E a Patria rica de immortais memorias" (XX, 87: 5-8). Afinal, quem "nunca com rigor forçava a Gente / A feguilo" só podia ser amado como guia, pai, conselheiro, irmão, amigo e companheiro ${ }^{69}$.

Seguem-se as honras fúnebres, como nas epopeias clássicas (Cf. XX, 91-96. 100). Exemplo pedagógico dos contemporâneos do poeta ${ }^{70}$, "Luzo Annibal, Marte de Hefpanha" e triunfador de Roma fica imortalizado no epitáfio com que encerra o poema, à laia de epílogo trágico, mas também épico:

Mais que as feridas finto voffas dores, / Cruel vos acho, quando mais piedofa: / Vivì de enganos, morro de favores, / Não pudera fer morte mais ditofa" (XX, 59: 1-4. 60: 1-4).

68 "Perdefte a teus paffados o refpeyto, / Tirafte a Roma de vencer a gloria, / Mas fabe, que por efte infame feyto / Sempre infame feia tua memoria. / Nunca fofte gerado em cafto leyto, / Filho es de algua adulterina hiftoria, / Que o fangue dos Scipioës nunca podia / Produzir tam nefanda aleyvofia" (XX, 71).

69 "Que como por amor avaffalava / E nunca com rigor forçava a gente / A feguilo, que fempre amado achava / Quem o feguiffe voluntariamente; / Qual por Reftaurador o lamentava, / Qual por feu natural, qual por parente, / Qual por guia, por Pay, por confelheyro, / ual por Irmão, Amigo, \& companheyro" (XX, 85).

70 "Amigos defte tempo, digo, Amigos, / Do tempo, aquelles, que andorinhas manças / Vos apartais no Inverno dos perigos, / $\mathrm{E}$ vos chegais ao Eftio das bonanças; / Tomay exemplo aquî deftes Antigos / Que invergonhando eftão voffas mudanças / Não vos quero notar de ingratos loucos / Porque inda há bons Amigos, mas faõ poucos" (XX, 97). 
"Repara nefta calpa, ó caminhante,

Que solitária as cinzas acompanha

Daquelle Triumfador deffa triumphante

Roma; Luzo Annibal, Marte de Hefpanha.

Se, por treiçam da emula ignorante

Morre, fe immortaliza, \& mais a acanha:

Foy Monarcha, 6 Paftor fevero, \& grato;

Foy Rayo, hè cinza; foy em fim Viriato" (XX, 102).

\section{Conclusão}

Apesar de várias incongruências históricas ${ }^{71}$, o poema Viriato Trágico, de Brás Garcia de Mascarenhas, representa uma brilhante homenagem do poeta barroco português ao arquétipo lusitano da resistência heróica ao domínio do invasor estrangeiro, protagonizado pela Roma, ainda republicana, mas já imperialista do século II a.C.

Incentivo pedagógico aos seus contemporâneos, tal poema transcende, no entanto, a sua época, para se inscrever na matriz identitária das nações hispânicas, designadamente da Lusitânia, cujo território abrange hoje a quase totalidade de Portugal.

Herói épico e trágico, Viriato, tal como é configurado neste poema, brilha novamente hoje como um estóico exemplum do integer vir, do dedicado cidadão que consagra toda a sua vida ao serviço da comunidade que ama e é, por isso, apontado como padrão ilustrativo das maiores virtudes, como a fides, a paupertas, a libertas, a grauitas, a concordia, a clementia, a liberalitas, a auctoritas, a gloria.

Numa época que perdeu o valor da tradição épica como estruturante da identidade dos seus povos, importa reevocar a memória e o exemplo dos principais autores da sua História, como hoje fazemos aqui, em relação a Viriato, reequacionando tal registo não em termos de ultrapassado nacionalismo e enervante fundamentalismo, mas em termos de saudável

${ }^{71} \mathrm{~A}$ efabulação poética permite ao autor não respeitar rigorosamente a época do herói, ao fazê-lo participar na II guerra púnica, ao lado de Aníbal, ao trazer elefantes para o teatro de guerra da resistência hispânica a Roma, ao explorar a dimensão amorosa da traição a Viriato, ao confundir o nome dos generais romanos, entre outras liberdades poéticas. 
perspectivação pedagógica e comunitária. Se perdemos a consciência da nossa identidade colectiva, como podemos reivindicar o que quer que seja, como podemos reescrever a nossa História, como podemos edificar o futuro?

\section{Bibliografia}

Carlos de MesqutTa (1922), "O Viriato Trágico - Estudo crítico-literário", in António de Vasconcelos, Brás Garcia de Mascarenhas - estudo de investigação histórica. Coimbra, 377-399.

Hernâni Cidade "Viriato Trágico", in J.P. Coelho (1969), Dicionário de Literatura I. Porto, 614.

J.V. de Pina Martins (1996), "Estudo sobre o valor literátio do Viriato Trágico, de Brás Garcia de Mascarenhas", in Viriato Trágico em poema heróico, escrito por Brás Garcia Mascarenhas, reed. fac-similada. Lisboa, IX-XCVIII.

António J. Saraiva e Óscar Lopes (s.d.), História da Literatura Portuguesa. Porto, 395-396. 